\title{
Metastatic salivary duct carcinoma in cardiac and pleural effusions: A case report with immunocytochemical analysis for androgen receptor and HER2
}

\author{
HIROKO ITO $^{1}$, MITSUAKI ISHIDA ${ }^{1}$, KAORI SANDO ${ }^{1}$, KIMIAKI OKANO ${ }^{1}$, YUSUKE EBISU ${ }^{1}$, \\ TAKUO FUJISAWA $^{2}$, HIROSHI IWAI ${ }^{2}$ and KOJI TSUTA ${ }^{1}$ \\ ${ }^{1}$ Department of Pathology and Laboratory Medicine; ${ }^{2}$ Department of Otolaryngology, \\ Kansai Medical University, Hirakata, Osaka 573-1010, Japan
}

Received August 1, 2018; Accepted October 15, 2018

DOI: $10.3892 / \mathrm{mco} .2018 .1747$

\begin{abstract}
Salivary duct carcinoma (SDC) is a relatively rare highly aggressive salivary gland tumor. Although SDC shows frequent lymph node and distant metastases, the presence of neoplastic cells in the pleural effusion is extremely rare. In this report, we describe the first documented cytological case of metastatic SDC in cardiac and pleural effusions with immunocytochemical analyses for androgen receptor (AR) and human epidermal growth factor receptor (HER)2. A 52-year-old Japanese male developed cardiac tamponade and respiratory discomfort after surgery and chemo-radiation therapy for SDC of the right submandibular gland. Aspiration of the cardiac and pleural effusions was performed. The Papanicolaou-stained cytological specimens of cardiac and pleural effusions showed that numerous small ball-like or papillary structures were present in an inflammatory background. The neoplastic cells had rich granular cytoplasm and large round to oval nuclei containing conspicuous nucleoli. Immunocytochemical analyses clearly demonstrated positivity for AR and strong membranous expression of HER2 in the neoplastic cells. Accordingly, a cytodiagnosis of metastatic SDC was made. Recently, HER2-targeted or AR deprivation therapy have been introduced for patients with SDC, therefore, determination of expression profiles of AR and HER2 may be crucial for developing a treatment strategy for patients with metastatic SDC. According to the results of the present report, immunocytochemical analyses for AR and HER2 in the effusion specimens may be useful for determination of a treatment strategy for patients with metastatic SDC.
\end{abstract}

Correspondence to: Dr Mitsuaki Ishida, Department of Pathology and Laboratory Medicine, Kansai Medical University, 2-5-1, Shinmachi, Hirakata, Osaka 573-1010, Japan

E-mail: ishidamt@hirakata.kmu.ac.jp

Key words: salivary duct carcinoma, pleural effusion, cardiac effusion, androgen receptor, human epidermal growth factor receptor 2

\section{Introduction}

Salivary duct carcinoma (SDC) is a relatively rare highly aggressive tumor, accounting for approximately $10 \%$ of all salivary gland malignancies (1). This type of tumor is characterized histopathologically by proliferation of neoplastic cells containing large round to oval nuclei with conspicuous nucleoli and rich eosinophilic cytoplasm, occasionally accompanied by comedonecrosis, which resembles high-grade breast carcinoma (1). The immunohistochemical characteristics of SDC include overexpression of human epidermal growth factor receptor (HER) 2 and positivity for androgen receptor (AR) $(1,2)$.

Although SDC shows a high frequency of lymph node metastases and distant metastases including in the lung, liver, brain, and bone (1), metastasis in the pleural effusion is extremely rare (3-5).

In this report, we describe the first documented cytological case of metastatic SDC in the cardiac and pleural effusion with immunocytochemical analyses for AR and HER2.

\section{Case report}

A 50-year-old Japanese male underwent surgery for a right submandibular gland tumor, which was diagnosed as SDC, and chemo-radiation therapy was added. At the age of 52, he was found to have nodules in the bilateral lungs, and subsequently cardiac tamponade and respiratory discomfort developed due to cardiac and pleural effusions. Aspiration of the cardiac and pleural effusions was performed. He has been followed-up at our hospital until now, and is alive with disease (brain metastasis) 4 months after development of cardiac tamponade. No resection of the lung nodules and brain metastasis was performed. The present patient has not been received HER2-targeted or AR deprivation therapy yet. The study was approved by the institutional review board of our hospital (approval no. 2016646), and we obtained patient consent according to our hospital policy.

Specimens of the cardiac and pleural effusions were stained with Papanicolaou stain. Formalin-fixed and paraffin-embedded specimens of the resected submandibular 
A

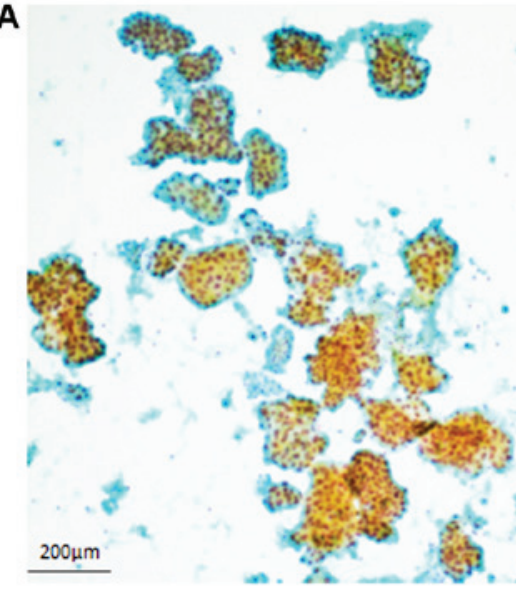

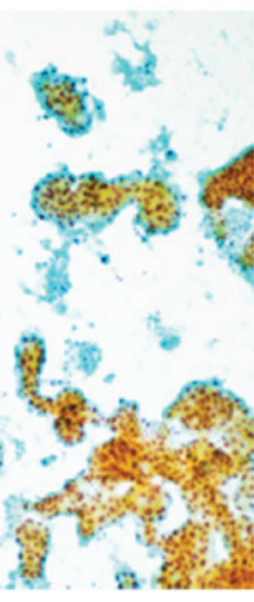

B

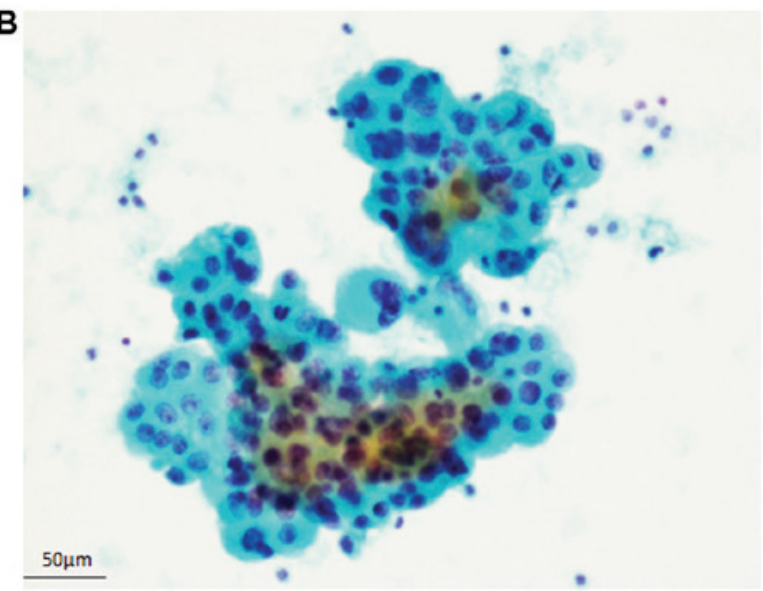

Figure 1. Cytological findings of the cardiac and pleural effusions. (A) Many small ball-like or papillary clusters in an inflammatory background (Papanicolaou stain, x100). (B) The neoplastic cells have rich granular cytoplasm and large round to oval nuclei with conspicuous nucleoli (Papanicolaou stain, x400).

A

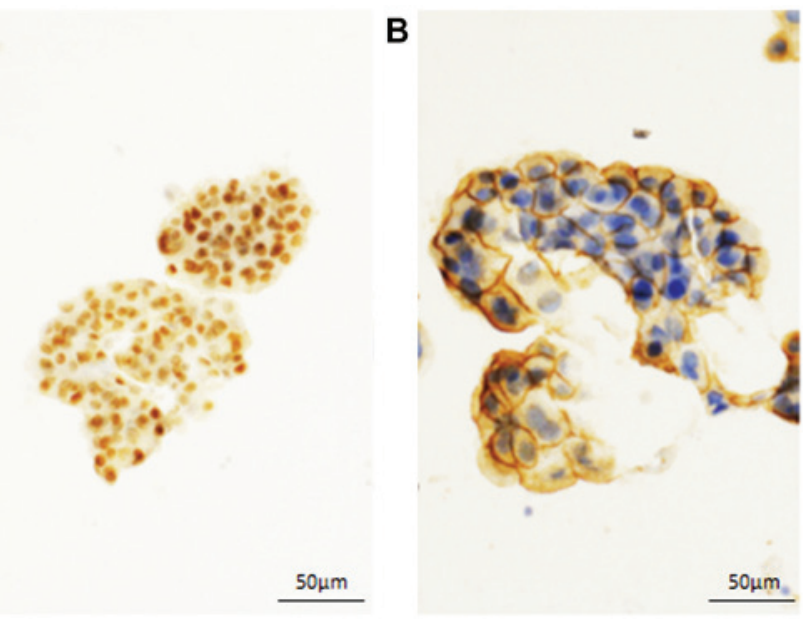

Figure 2.Immunocytochemical findings of the cardiac effusion. (A) Androgen receptor is expressed in the nuclei of the neoplastic cells (x400). (B) Human epidermal growth factor receptor 2 is strongly expressed in the membrane of the neoplastic cells (x400).

gland tumor were processed for routine histological examination and immunohistochemical analyses.

In this report, immunohistochemical and immunocytochemical analyses were performed using an autostainer (XT System Benchmark, Roche Diagnostics, Basel, Switzerland). The primary antibodies used in this report were a rabbit monoclonal antibody against AR (SP107, Roche Diagnostics) and a rabbit monoclonal antibody against HER2 (4B5, Roche Diagnostics).

Cytological findings of the cardiac and pleural effusions. The cytological specimens of the cardiac and pleural effusions showed the same features. The Papanicolaou smears demonstrated numerous small ball-like or papillary clusters in an inflammatory background (Fig. 1A). These neoplastic cells had large round to oval nuclei with conspicuous nucleoli and coarse chromatin, and relatively rich granular cytoplasm (Fig. 1B).

Immunocytochemical findings. AR was diffusely expressed in the nuclei of the neoplastic cells (Fig. 2A). Strong membranous expression of HER2 was noted in the tumor cells (Fig. 2B).
Accordingly, a cytodiagnosis of metastatic SDC in the cardiac and pleural effusions was made with consideration of the clinical history.

Histopathological findings of the submandibular gland tumor. The resected specimen showed infiltrative neoplastic growth composed of variable-sized nests or irregular glandular formation with invasion into the fatty tissue and nerve bundles surrounding the submandibular gland (Fig. 3A). The neoplastic cells had rich eosinophilic cytoplasm and large round to oval nuclei with conspicuous nucleoli (Fig. 3B). Mitotic figures were easily found, and comedonecrosis was also noted. Metastatic carcinoma was present in the right level III, IV, and V lymph nodes (10/45).

Immunohistochemical findings. The neoplastic cells diffusely expressed for AR (Fig. 4A). Strong membranous expression of HER2 was noted in the neoplastic cells (Fig. 4B). Accordingly, a final diagnosis of SDC was made.

\section{Discussion}

In this article, we describe the first documented case of metastatic SDC in cardiac and pleural effusions. Although SDC shows an aggressive clinical course and lung metastasis occasionally occurs, the presence of carcinoma cells of SDC in the pleural effusion is extremely rare. It is very important to detect the carcinoma cells in cardiac and pleural effusions because of staging and therapeutic strategy for patients. Presence of cardiac effusion is clinically important because cardiac tamponade can be developed, as seen in the present patient. Only three cytological cases of pleural effusion have been reported in the literature (3-5), and no cytological report of SDC in cardiac effusion has been published. Table I summarizes the clinicocytological features of the previously reported cases as well as the present one. The characteristic cytological features of fine-needle aspiration of SDC of the salivary gland are as follows: i) Presence of three-dimensional clusters, flat sheets, cribriform glands, or dissociated neoplastic cells in a necrotic background; and ii) large polygonal to spindle-shaped neoplastic cells with rich and finely granular 

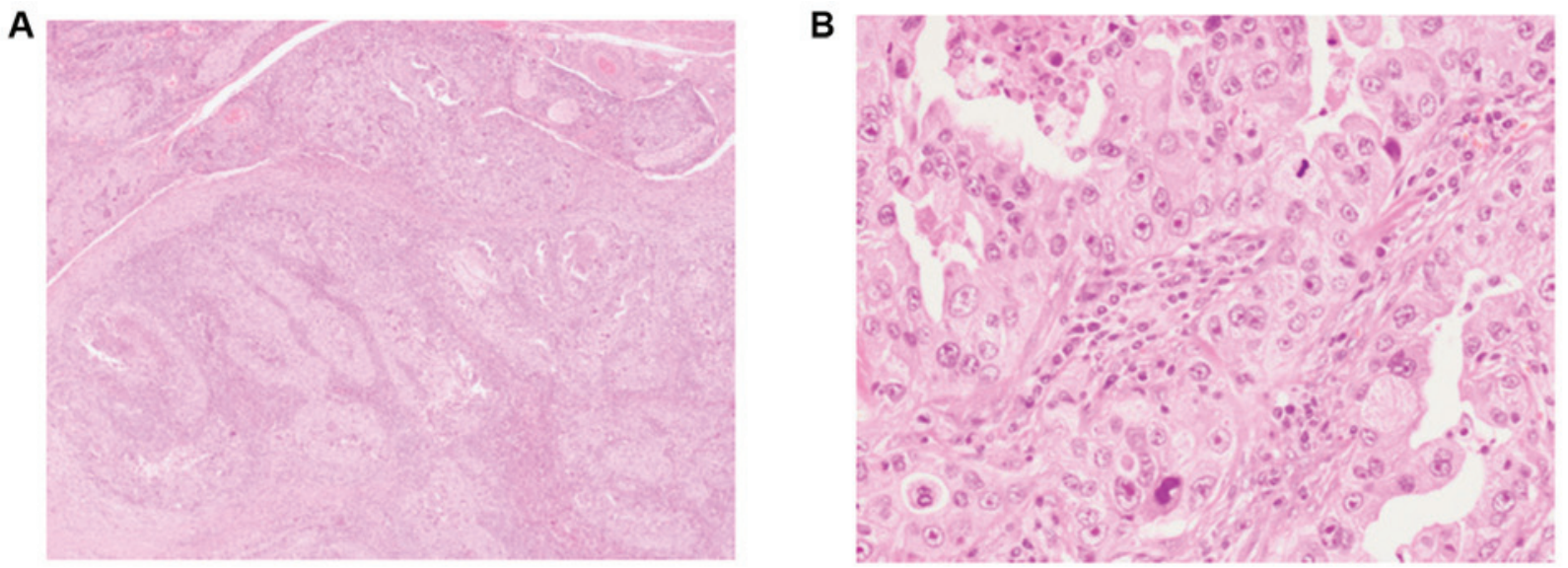

Figure 3. Histopathological features of the right submandibular gland tumor. (A) Infiltrative neoplastic growth composed of variable-sized nests or irregular glandular formation (H\&E, x40). (B) The neoplastic cells have rich eosinophilic cytoplasm and large round to oval nuclei containing conspicuous nucleoli (H\&E, x400).
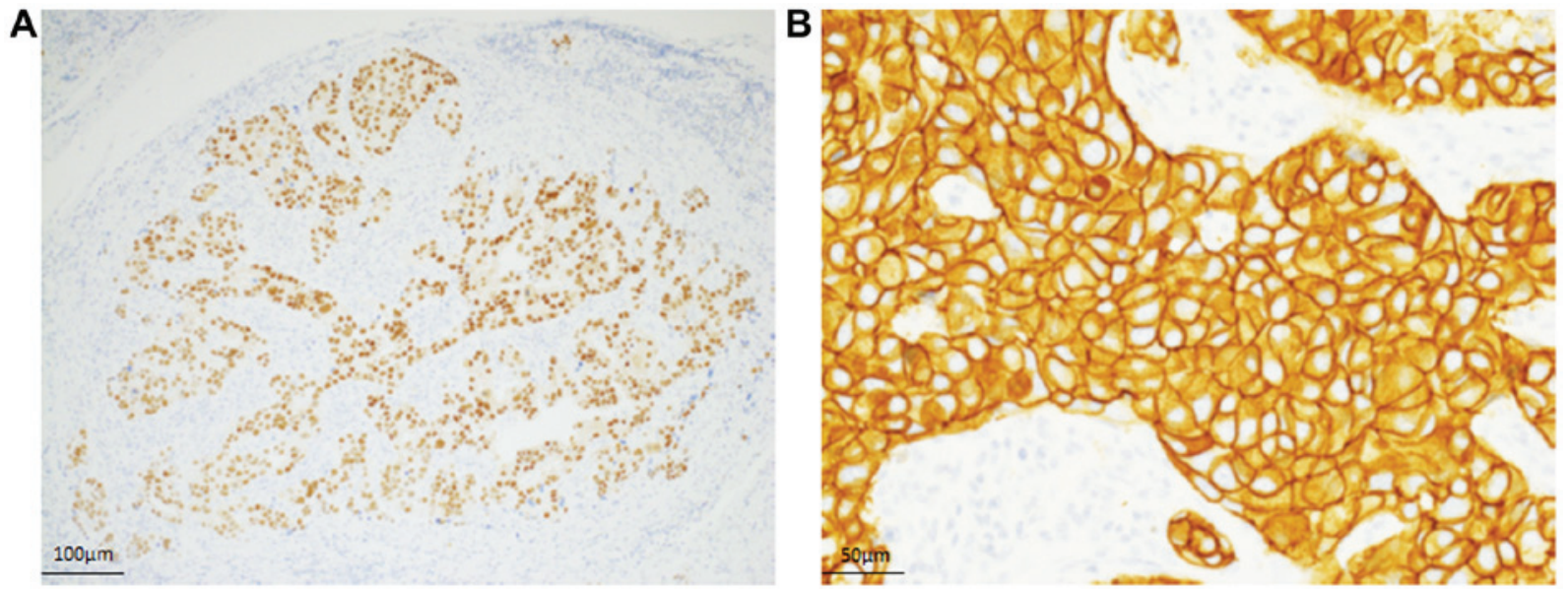

Figure 4. Immunohistochemical features of the right submandibular gland tumor. (A) Androgen receptor is diffusely expressed (x200). (B) Strong membranous expression of human epidermal growth factor receptor 2 is noted $(\mathrm{x} 400)$.

(apocrine-like) cytoplasm and large round to oval nuclei containing coarse chromatin and conspicuous nucleoli $(6,7)$. Although the cytological features of the pleural and cardiac effusions of the previously reported cases and the present case were fundamentally the same as the above-mentioned cytological features, the presence of ball-like neoplastic cell clusters (and papillary clusters) may be a characteristic feature of the neoplastic cells present in the pleural and cardiac effusions (Table I). Murata et al pointed out that other histological subtypes of salivary gland carcinoma can present ball-like clusters in the pleural effusion (5). Therefore, recognition of this finding may be important for making differential diagnoses of metastatic carcinoma present in the pleural and cardiac effusions.

The most common type of malignant cells present in the pleural effusion is adenocarcinoma, and the most common original sites are breast and lung (8). Development of pleural metastasis of salivary gland carcinoma is extremely rare, and only a few cases of adenoid cystic carcinoma $(9,10)$, mucoepidermoid carcinoma (11), and myoepithelial carcinoma (12) as well as SDC (3-5) have been reported. Therefore, metastatic SDC in the pleural effusion must be differentiated from metastatic breast carcinoma because SDC resembles high-grade breast carcinoma. Expression of AR is a characteristic finding of SDC (2), which was useful for making the cytodiagnosis of metastatic SDC in the present case. However, approximately $70 \%$ of breast cancer shows positive immunoreactivity for AR (13). Therefore, cytomorphological and immunocytochemical features as well as consideration of clinical history are important for making a correct diagnosis.

It is well recognized that overexpression of HER2 is occasionally observed in SDC (2). Murata et al demonstrated overexpression of HER 2 and HER 3 in metastatic SDC using a cytological specimen of the pleural effusion (5). Our presented case also clearly demonstrated AR and HER2 expression in SDC using the cytological specimens of the cardiac and pleural effusions. Recently, some classifications of molecular subtypes of SDC have been proposed according to that of breast carcinoma. Di Palma et al proposed molecular subgroups of SDC according to the immunoprofiles of HER2, AR, epidermal growth factor receptor, and keratin 5/6: Namely, luminal androgen receptor-positive, HER2, and basal-like subtypes (14). Takase et al proposed molecular subgroups of SDC: Namely, apocrine A (AR ${ }^{+} / \mathrm{HER} 2 / \mathrm{Ki}-67$ low), 
Table I. Clinicocytological features of metastatic salivary duct carcinoma in the pleural effusion.

\begin{tabular}{|c|c|c|c|c|c|c|}
\hline Case no. & Age & Sex & Original site & Cytological features & Immunocytochemical features & (Refs.) \\
\hline 1 & 76 & Male & $\begin{array}{l}\text { Submandibular } \\
\text { gland }\end{array}$ & $\begin{array}{l}\text { Small clusters with subtle } \\
\text { cribriform features. The tumor cells } \\
\text { have finely granular apocrine-type cytoplasm. }\end{array}$ & $\begin{array}{l}\operatorname{AR}(+), \operatorname{HER} 2(+) \\
\text { (cell block) }\end{array}$ & (3) \\
\hline 2 & 57 & Male & $\begin{array}{l}\text { Submandibular } \\
\text { gland }\end{array}$ & $\begin{array}{l}\text { Numerous cell clusters. } \\
\text { The neoplastic cells have rich } \\
\text { granular cytoplasm and eccentric large round } \\
\text { to oval nuclei containing conspicuous nucleoli. }\end{array}$ & $\mathrm{AR}(+)$ & (4) \\
\hline 3 & 46 & Male & $\begin{array}{l}\text { Parotid } \\
\text { gland }\end{array}$ & $\begin{array}{l}\text { Small ball-like cell clusters. } \\
\text { The tumor cells have apocrine-like } \\
\text { cytoplasm and pyknotic chromatin. }\end{array}$ & $\begin{array}{l}\operatorname{AR}(+), \operatorname{HER} 2(+), \\
\operatorname{HER} 3(+)\end{array}$ & (5) \\
\hline $\begin{array}{l}\text { Present } \\
\text { Case }\end{array}$ & 52 & Male & $\begin{array}{l}\text { Submandibular } \\
\text { gland }\end{array}$ & $\begin{array}{l}\text { Numerous papillary and ball-like cell } \\
\text { clusters. The tumor cells have large nuclei } \\
\text { with conspicuous nucleoli and rich cytoplasm. }\end{array}$ & $\operatorname{AR}(+), \operatorname{HER} 2(+)$ & \\
\hline
\end{tabular}

$\mathrm{AR}$, androgen receptor; HER, human epidermal growth factor receptor.

apocrine $\mathrm{B}\left(\mathrm{AR}^{+} / \mathrm{HER} 2 / \mathrm{Ki}-67 \mathrm{high}\right)$, apocrine HER 2 $\left(\mathrm{AR}^{+} / \mathrm{HER} 2^{+}\right)$, HER 2 enriched $\left(\mathrm{AR}^{-} / \mathrm{HER} 2^{+}\right)$, and double negative subtypes (2). Moreover, HER2-targeted therapy or AR deprivation therapy have been introduced for patients with SDC $(15,16)$. Although the present patient has not been received HER2-targeted or AR deprivation therapy, the determination of the above-mentioned molecular subtypes may be crucial for developing a treatment strategy for patients with SDC. According to the results in the present report, immunocytochemical analyses for AR and HER 2 in the effusion specimens may be useful for determination of the treatment strategy in patients with metastatic SDC, especially in the patients who are not performed biopsy or resection of the metastatic tumor, as the present patient.

\section{Acknowledgements}

Not applicable.

\section{Funding}

No funding was received.

\section{Availability of data and materials}

The datasets used and analyzed during the current study are available from the corresponding author on reasonable request.

\section{Authors' contributions}

HIt, MI, KS, KO contributed to cytological diagnosis and manuscript preparation. YE performed immunocytochemical and immunohistochemical stainings. MI, KT performed histopathological diagnosis. TF, HIw contributed to patient data collection. The final version of the manuscript has been read and approved by all authors.

\section{Ethics approval and consent to participate}

Not applicable.

\section{Patient consent for publication}

Not applicable.

\section{Competing interests}

The authors declare that they have no competing interests.

\section{References}

1. Nagao T, Licitra L, Loening T, Vielh P and Williams MD: Salivary duct carcinoma. In: WHO Classification of Tumours of Head and Neck Tumours (4th edition). El-Naggar AK, Chan JKC, Grandis JR, Takata T and Slootweg PJ (eds). IARC, Lyon, pp173-174, 2017.

2. Takase S, Kano S, Tada Y, Kawakita D, Shimura T, Hirai H, Tsukahara K, Shimizu A, Imanishi Y, Ozawa H, et al: Biomarker immunoprofile in salivary duct carcinomas: Clinicopathological and prognostic implications with evaluation of the revised classification. Oncotarget 8: 59023-59035, 2017.

3. Huss J, Conrad R, Hirschowitz S and Moatamed N: Pleural fluid metastases of salivary duct carcinoma: A case report and review of the literature. Cytojournal 11: 4, 2014.

4. Iwamoto N, Ishida M, Kagotani A, Kasuga N, Hayashi Y, Iwai M, Miyahira Y and Kushima R: A case of salivary duct carcinoma in the pleural effusion successfully diagnosed by immunocytochemical analysis. J Jpn Soc Clin Cytol 55: 412-415, 2016.

5. Murata K, Kawahara A, Ono T, Takase Y, Abe H, Naito Y and Akiba J: HER2/HER3-positive metastatic salivary duct carcinoma in the pleural effusion: A case report. Diagn Cytopathol 46: 429-433, 2018.

6. Moriki T, Ueta S, Takahashi T, Mitani M and Ichien M: Salivary duct carcinoma: Cytologic characteristics and application of androgen receptor immunostaining for diagnosis. Cancer 93: 344-350, 2001.

7. Elsheikh TM, Bernacki EG Jr and Pisharodi L: Fine-needle aspiration cytology of salivary duct carcinoma. Diagn Cytopathol 11: 47-51, 1994.

8. Sears D and Hajdu SI: The cytologic diagnosis of malignant neoplasms in pleural and peritoneal effusions. Acta Cytol 31: 85-97, 1987. 
9. Florentine BD, Fink T, Avidan S, Braslavsky D, Raza A and Cobb CJ: Extra-salivary gland presentations of adenoid cystic carcinoma: A report of three cases. Diagn Cytopathol 34: 491-494, 2006.

10. Torre W, Comellas M and Cuesta M: Massive pleural effusion as isolated manifestation of metastatic spread of salivary adenoid cystic carcinoma. Respir Med 91: 169-170, 1997.

11. Matsushita I, Takeda T, Kobayashi TK, Tanaka B and Sawaragi I Mucoepidermoid carcinoma of the salivary gland in pleural fluid. A case report. Acta Cytol 27: 525-528, 1983.

12. Bhambra AC, Zhang Y, Huang EC, Bishop J, Matin M and Afify A: Pleural fluid metastases of myoepithelial carcinoma: A case report and review of the literature. Cytojournal 13: 13, 2016.

13. Cimino-Mathews A, Hicks JL, Illei PB, Halushka MK, Fetting JH, De Marzo AM, Park BH and Argani P: Androgen receptor expression is usually maintained in initial surgically resected breast cancer metastases but is often lost in end-stage metastases found at autopsy. Hum Pathol 43: 1003-1011, 2012.

14. Di Palma S, Simpson RH, Marchiò C, Skálová A, Ungari M, Sandison A, Whitaker S, Parry S and Reis-Filho JS: Salivary duct carcinomas can be classified into luminal androgen receptor-positive, HER 2 and basal-like phenotypes. Histopathology 61: 629-643, 2012.
15. Limaye SA, Posner MR, Krane JF, Fonfria M, Lorch JH, Dillon DA, Shreenivas AV, Tishler RB and Haddad RI: Trastuzumab for the treatment of salivary duct carcinoma. Oncologist 18: 294-300, 2013.

16. Locati LD, Perrone F, Cortelazzi B, Lo Vullo S, Bossi P, Dagrada G, Quattrone P, Bergamini C, Potepan P, Civelli E, et al: Clinical activity of androgen deprivation therapy in patients with metastatic/relapsed androgen receptor-positive salivary gland cancers. Head Neck 38: 724-731, 2016.

This work is licensed under a Creative Commons Attribution-NonCommercial-NoDerivatives 4.0 International (CC BY-NC-ND 4.0) License. 